\title{
Error Analysis in Chinese Initials Made by Bangladeshi Learners at Elementary Level
}

\author{
Nilu Akter \\ Department of Teaching Chinese to the Speakers of Others languages, Guizhou University \\ Guizhou, China
}

Tel: 86-130-8780-7615Ｅ-mail: nilaakther789@gmail.com

Received: April 5, 2021

doi:10.5296/ijl.v13i3.18694
Accepted: May 24, 2021

Published: May 30, 2021

URL: https://doi.org/10.5296/ijl.v13i3. 18694

\begin{abstract}
Chinese initials play an inevitable role in learning Chinese as a second language. Without the proper knowledge of Chinese initials, learners fail to communicate with people smoothly. Therefore, learners from different countries face different difficulties in learning Chinese initials. The pronunciation of Chinese consonants is not easy for foreigners, especially for Bangladeshi learners. Therefore, errors occur in the Chinese initials of Bangladeshi learners.

Although Bangladeshi students often encounter difficulties learning Chinese initials, no comprehensive research done in this area. This research aims to investigate the pronunciation errors of Chinese initials made by Bangladeshi learners. To know the types of initials errors and the reason behind these errors, the error analysis hypothesis, and the contrastive analysis hypothesis was used to analyze the data. However, 20 Bangladeshi students at the elementary level were chosen as the research participants. In this research, a questionnaire survey, interview and comparative analysis were used as research methods.

The common finding is that the initials error of Bangladeshi learners occurs in labial, alveolar, velar, retroflex, dental, and palatal consonants. Among them, the highest rate of error has been found in the pronunciation of retroflex, dental, palato-alveolar consonants. The research found that the reason for initials errors of Bangladeshi Chinese learners is the negative transfer of mother tongue, similar phonetic symbols, lack of learning motivation and strategy etc. Finally, the researcher provides some suggestions to correct the pronunciation of initials errors of Bangladeshi Chinese learners.
\end{abstract}

Keywords: Bangladeshi learners, Elementary Chinese, Chinese initials, Initials error 


\section{Introduction}

Bangladesh is one of the largest trading partners of China in south Asia. It has become an active member of China's Silk Road project since 2016. At present, the number of Bangladeshi learners in Chinese is increasing rapidly. Chinese is a widely used language compared to other alphabetic languages like English, French, and Spanish languages. Based on the level of difficulties, among 67 languages, Chinese is defined as the category of super-hard languages (Ranjan, 2010).

As a second language, learning Chinese is one of the most popular languages among Bangladeshi students. Bangladeshi learners often encounter difficulties in learning Chinese. They have a problem with the acquisition of Chinese initials, finals, and tones. Based on origin, both Chinese and Bangla derive from two different language families. However, Chinese is a tonal language, while Bangla is an alphabetic language. Therefore, they have immense differences in linguistics elements and systems. So It's not easy for Bangladeshi students to acquire Chinese accurately. As a result, some common errors often occur in the initials of Bangladeshi students.

\subsection{A Brief Introduction to Chinese Phonology}

Chinese is considered one of the hardest and ambiguous languages for its unique characters like tone and writing systems. Like other languages, Chinese characters are not phonetic and not alphabetic. It is mainly ideographic or logographic where characters are represented by picture or symbol. As a result, it's always hard to present the correct phonology of the Chinese language. To represent the sounds of Chinese characters, pinyin(拼音) system is used, literally means "spell out the sound". It is the easiest and primary way to learn Chinese pronunciation for foreigners. However, Pinyin uses Roman alphabets to represent the sounds of Chinese. All the letters of the English alphabet also use in this pinyin system except consonants "V". In this pinyin system, initials and finals are the core elements. As pinyin has similarities with the English alphabet, non-native speakers of Chinese easily get confused with the pronunciation of Chinese initials and finals. So non-native speakers of Chines should be kept in mind that pinyin represents the sound of Chinese, not English. In Chinese, phonology generally indicates its initials (consonants sounds), finals (vowel sounds), and tones.

Among linguists and scholars, the specific number of initials and finals is a matter of dispute. Some believe the exact number of Chinese initials is 21 while others agree on 22 . However, some researchers also believe the number of Chinese vowels (finals) is mainly 6 while others believe in 5. "if we exclude the two 'apical vowels' and the retroflex vowel, standard Chinese has five vowel phonemes" (Duanmu, 2007: 35).

Moreover, Chinese is a tonal language and it has 4 tones. These are yin ping (High-level tone), yang pin (High rising tone), shang sheng (Falling rising tone), and qu sheng (Falling tone), etc. There is also a neutral tone present in Chinese. However, without the accurate pronunciation of tone, one can not produce the Chinese language properly. It is the basic requirement of standard Chinese pronunciation. Word meaning can be changed depending on 
the use of tone as the same word may have different tones and different meanings. So if one wants to be a master of the Chinese language, certainly he should learn the proper pronunciation of Chinese tone.

\subsection{Importance of Learning Initials in Chinese as a Foreign Language}

In language acquisition, phonetic acquisition is one of the core elements of a language. Without the proper knowledge of phonetics in the second language, no one can communicate accurately with people. So in the process of learning Chinese, correct phonetics learning is a must for a learner. The primary purpose of learning Chinese initials is to cultivate learners' communicative skills in second language acquisition.

Therefore, the correct pronunciation of Chinese initials is inevitable to communicate successfully. The meaning of a word may be changed based on the pronunciation of initials as Chinese has some initials which have similar pronunciation. For example, Chinese dental sounds such as z, c, s; retroflex sounds such as zh, ch, sh, and alveo-palatal sounds j, q, x etc.

As a result, non-speakers of Chinese get confused and make mistakes. During learning Chinese initials, foreigners of different countries face difficulties. The error rate is higher than the other phonetic elements. For Malay students, the pronunciation of consonants constitutes the highest number of errors $(68.29 \%)$ as compared to the tone $(13.66 \%)$ and vowel $(18.5 \%)$ (Khor1, Mah \&Chow, 2017).

\subsection{Pronunciation Errors in Chinese Initials Made by Bangladeshi Learners}

Chinese initial is one of the core elements of the Chinese language. Non-native speakers of Chinese face obstacles acquiring initials especially Bangladeshi Chinese learners. However, Bangladeshi learners encounter difficulties in learning Chinese initials, which barrier their communication skills. The forms of initial consonants error of Bangladeshi Chinese learners are complex, and the error rate is comparatively high than other linguistic forms ( $\mathrm{Li}, 2013)$.

The differences between learners first and target language are also responsible for initials errors. However, Bangla and Chinese both originated from different language families. Bangla originated from the Indo-European language. On the other hand, the Chinese derived from the Sino-Tibetan language family.

\subsection{Objective of the Research}

In this study, Bangladeshi Chinese learners are the experimental research object. Additionally, some specific objectives of this research are:

- To investigate the types of errors in the pronunciation of initial made by Bangladeshi learners.

- To analysis the causes of initials errors of Bangladeshi Chinese learners.

\subsection{Rationale of the Study}

The main objective of the research is to know the types of initials errors of Bangladeshi Chinese learners. Simultaneously, researcher also tries to find out the reason behind these 
errors. Bangladeshi learners often encounter obstacles in learning initials of Chinese. However, a study on initials error of Chinese initials has become a principal part of Linguistics and teaching Chinese department.

This research tries to help learners to acquire Chinese initials accurately. Besides, some effective teaching and learning methods also discussed in this study so that learners can find out and correct their errors. Furthermore, this study will be helpful for Bangladeshi Chinese learners to acquire the better pronunciation of Chinese initials. It also contributes to the knowledge of those who are willing to conduct similar researches in the area.

\section{Literature Review}

\subsection{Introduction}

This study deals with analyzing the initials errors of Bangladeshi Chinese learners at the elementary level. The consonant is known as initials in Chinese that locate at the very beginning of Hanyu pinyin. As a primary stage of learning Chinese language, the importance of learning initials is inevitable. Therefore, at first, learners should master the pronunciation characteristics of Chinese initials as "Pronunciation is the sound of human speech, is the semantic expression form, and also is the material shell of language" (Huang \& Liao, 2017). It can also affect proper communication. Therefore, Bangladeshi students often make errors in producing initials as Chinese initials are different from Bangla.

Generally, errors denote "an actual learning process taking place and that the learner has not yet mastered or shown a well-structured competence in the target language" (Hendrickson, 1987: 357). Therefore, error analysis indicates that interference from the learner's mother tongue is not the only reason for committing errors in his target language.

\subsection{Previous Research Done on Initials Errors}

The research on the Chinese initials of Bangladeshi learners is almost blank. However, researcher found three researches related to Chinese initials of Bangladeshi learners on Chinese language. A comprehensive review of the current academic research on Chinese Initials of Bangladeshi learners is as follows:

Li (2013) studied the common mistakes of Bangladeshi learners in initials, finals, and tones that are occurred during the process of learning Chinese. In this study, the researcher found the initials errors of Bangladeshi Chinese learners in the aspirated non-aspirated, unvoiced sounds and confusion of place of articulation. The researcher also discussed the teaching difficulties of Chinese in Bangladesh and provided suggestions to solve these problems.

Qin (2014) studied on Chinese Phonetics of Bangladesh BIT Sixth Grade Students. The research found error occurs in the seven initials with error rates more than or equal to $50 \%$. These are c, zh, q, ch, p, t, k consonants. Among these, the initials c and zh have the highest error rate which is $94 \%$ and $88 \%$. Furthermore, the error forms of $\mathrm{p}, \mathrm{t}$, and $\mathrm{k}$ belong to the error type that aspirated sound becomes un-aspirated. Finally, the researcher concluded that Bangladeshi learners often make mistakes in initials because they pronounce Chinese initials according to the pronunciation of the English consonants. 
Li (2016) divided the difficulty level of Chinese initials of Bangladeshi learners into five-level. The researcher put $\mathrm{m}, \mathrm{f}, \mathrm{n}, \mathrm{l}$ are in the first level; $\mathrm{b}, \mathrm{d}, \mathrm{g}$ are in the second level; $\mathrm{p}, \mathrm{t}$, $\mathrm{k}, \mathrm{h}$ are in the third level; j, q, x are in the fourth level; zh, ch, sh, r, z, c, are in the fifth level of difficulty. Based on the difficulty level, the higher the level is, the more difficult it is. From the analysis, the researcher showed that the error rate of the dental alveolar sound is higher than palatal alveolar sound. Furthermore, the researcher also found that the negative migration of the mother tongue, the generalization of the target language, and factors of students are responsible for initials errors of Chinese initials.

There is some research found on initials errors of non-native speakers of Chinese are as follows:

Sukarto et al. (2019) investigated the phonological differences of Chinese and Indonesian languages and their impact on Chinese conversation. The research shows that although some similar pairs of consonants present in both languages, they produce differently based on place and manner of articulations. As a result, Indonesian students often get confused with these Chinese consonants when they pronounce them. The main reason for Indonesian students committing errors in Chinese consonants as the Indonesian language does not distinguish based on aspirated and un-aspirated sounds, only distinguish voice and voiceless sounds. So when they produce plosive $\mathrm{p}, \mathrm{t}, \mathrm{k}$ sounds they tend to add $[\mathrm{h}]$ consonants. Besides, they often get confused with the pronunciation of $\mathrm{c}$ and $\mathrm{s}, \mathrm{z}$ and $\mathrm{r}$ consonants. Moreover, Indonesian students also face difficulties reading Chinese retroflex consonants zh, ch, sh. The authors stated that these consonants are more difficult to pronounce than others as these sounds are absent in their mother tongue.

Chandra \& Sukuma (2020) also studied the Chinese initials teaching plan for Indonesian Chinese learners at the primary level. In this study, the researchers presented three teaching plans for Chinese learners at the primary level. The teaching methods include teaching initials from easy to difficult. Authors suggested an arranged for initials to follow like bilabial, labiodental, alveolar, velar, alveo-palatal, dental, and retroflex initials. First, teachers read the Chinese initials then let students read or imitate the pronunciation of initials. Secondly, provide an adequate initials exercise that can be presented by cartoon images so that students can better understand the pronunciation of Chinese initials. Furthermore, the teachers also compare the similarities and differences between Chinese and Indonesian consonants. It may be helpful for learners to understand the pronunciation differences between Chinese and Indonesian initials.

Yang and Yu (2019) researched the perception and production of the Chinese affricate consonants of English Chinese learners at the primary and intermediate levels.They experimented on six Chinese affricate consonants such as z, c, zh, ch, j, and q. The research shows that English native speakers of Chinese perform well like the native speakers in the discrimination task than identification task. Moreover, L2 learners face different difficulties in producing different affricate sounds due to the negative transfer of the mother tongue. However, the un-aspirated palatal $\mathrm{j}$ was better identified than the aspirated palatal $\mathrm{q}$ but aspirated retroflex ch was better identified than the un-aspirated retroflex zh consonant. The 
learners produce the aspiration in dental better than non-dental. The authors found that intermediate learners pronounce well than the beginning level of learners because of some learning effect.

Wang and Chen (2019) studied the identification of Chinese consonants by English CFL learners at two different proficiency levels. They surveyed ten Chinese consonants at the Chinese learners at primary and intermediate levels. They found that consonants $\mathrm{zh}, \mathrm{q}, \mathrm{c}, \mathrm{x}$ show the lowest identification scores and accuracy rate than other consonants. Among them, consonants zh, q, c intermediate level learners better perform than primary level learners. However, data show that learners' perception scores of Chinese consonants are closely related to L2 to L1 assimilation patterns. These results have similarities to the research on English CFL learners' perception and production (Wang and Chen, 2020). This research predicted that English CFL learners have more difficulties in perception than production in Chinese consonants.

Wang et al. (2019) studied on the present situation of the phonetic errors of foreign students. The authors found that the main cause of initials errors in Chinese, learners pronounce Chinese consonants according to their native language. The research also found that the wrong position of the tongue also responsible for initials errors such as sh, ch, zh, j, q, x, c, s, $z$, etc. Finally, researchers put forward feasible teaching strategies and suggestions for learners and teachers to solve the phonetic errors of foreign students.

$\mathrm{Xu}$ (2013) discussed the phonetic errors of Indian students in Chinese language learning. The author points out those students confuse with the pronunciation of $b, p, f, x$ sounds and the pronunciation of these sounds is not standard. Therefore, learners often pronounce $\mathrm{zh}$, ch, sh as $\mathrm{z}, \mathrm{c}, \mathrm{s}$, etc. On the other hand, learners produce $\mathrm{zh}$, ch, sh sounds similar to $\mathrm{j}, \mathrm{q}$, x sounds. They often pronounce $r$ as in English read.

Khor1 et al. (2017) collected and analyzed initials errors made by Malaysian undergraduates students. This research shows that Malay students encounter difficulties pronouncing retroflex and dental consonants due to the influence of their mother tongue. However, Malay students also face difficulties in producing aspirated sounds such as $\mathrm{zh}, \mathrm{ch}$, sh, and $\mathrm{r}$ because they are not familiar with the movement of their tongue and get confused. However, the students were not able to acquire the aspirated consonants like ch and c due to the absence of this phonetic feature in the Malay language.

Undoubtedly, the difficulty of learning Chinese pronunciation is different for students from different countries. It is much more difficult for Bangladeshi students to learn Chinese because of its unique characteristics. Therefore, when learning Chinese initials, learners need to follow some strategies that will help them to learn Chinese initials very effectively.

\subsection{Pronunciation Errors in Chinese Initials: A Theoretical Analysis}

This thesis mainly investigates and studies the errors of initials of Bangladeshi foreign students who have a basic level of Chinese. Moreover, it analyzes the types of errors and the reasons behind the errors and gives corresponding learning strategies and other suggestions. 


\subsubsection{Error Analysis Hypothesis}

Error analysis is one of the most popular theories in second language acquisition. It was first proposed by Stephen Pit Corder to analyze L2 errors. According to this theory, an error occurs as a result of the complexities of the second language. It is mainly focused on actually committed errors by L2 learners.

Corder (1967) mentioned that L2 errors are interesting because they can reflect some of the underlying linguistic rules. There are four steps in error analysis: collecting a sample of learner language, identification of errors, description, and classification of errors, explanation of errors (1974). However, according to Ellis (1997), an error occurs because the learner does not know what is correct that reflects gaps in learners' knowledge. Besides, there is a difference between mistake and error. Mistakes can be self-corrected whereas errors cannot be self-corrected (James, 1998). In other words, both L1, L2 learners make mistakes, but native speakers can recognize and correct mistakes.

\subsubsection{Contrastive Analysis Hypothesis}

Contrastive analysis indicates the similarities and differences between learners' first and second languages. It tries to explain why some features of a target language are more difficult to acquire than others. According to this hypothesis, L2 learners can easily acquire the features of a second language that are similar to their first language. On the other hand, features that are different or not present in learners' first language, learners encounter difficulties to acquire those elements. However, It is also assumed that by comparing learners first and target languages, L2 learners' error could be predicted.

According to Lado (1975), the contrastive analysis is not only to compare linguistic elements and linguistic systems between first language and second language but to compare and describe the background of the two languages.

Based on the error analysis and contrastive analysis, research data has been analyzed. In this research, error analysis is used to analyze the types of initials errors made by Bangladeshi learners to address the first research question. Moreover, contrastive analysis is used to discuss the similarities and differences between Chinese and Bengali consonants, to identify errors due to the negative transfer of the mother tongue.

Finally, by these two theories, the researcher addresses the research questions. It analyzes the similarities and differences of initials of the two languages. It also finds out the causes of the initials errors, such as negative transfer of mother tongue, differences between Chinese and Bangla Consonant systems, etc.

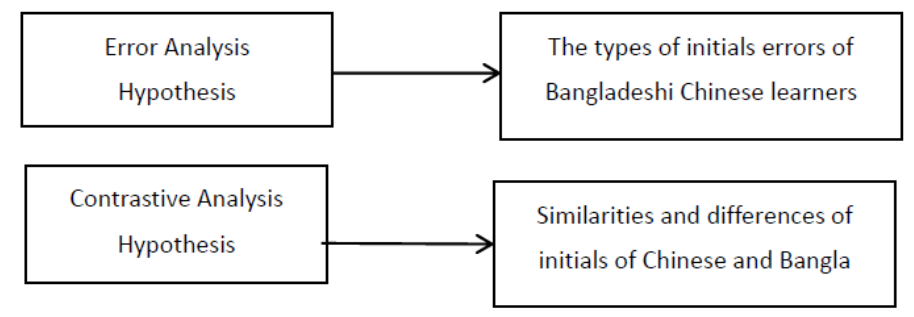

Figure 1. Conceptual framework 


\section{Research Methodology}

\subsection{Research Question}

1. What are the initial errors of Bangladeshi Chinese learners at the elementary stage?

2. What are the causes of initials errors of Bangladeshi Chinese learners'?

\subsection{Participants}

This study selects primary level (初级阶段) Bangladeshi students who study in China as the research participants. The research participants were 20 Bangladeshi students, where 14 boys and 6 are girls. Students have some basic knowledge of the Chinese language, but their Chinese level is not high as their Chinese level is the primary stage.

\subsection{Procedures}

In this research, questionnaire survey, interview, and comparative analysis methods were used as the research methods.

Firstly, the researcher conducted a questionnaire survey among the Bangladeshi Students in China who were at the elementary level of Chinese. In this research, the questionnaire contains 51 monosyllable words from the new HSK comprehensive books HSK 1-4 level and let Bangladeshi students read them aloud. The participants have an average HSK Chinese proficiency level of 3 and 4 . The test method is to record their pronunciation. The author then listened to the recordings one by one and analyzed the errors in monosyllabic words in Chinese initials.

Secondly, after conducting a questionnaire survey, the researcher also conducted a face-to-face interview among 15 participants. The main purpose of the interview is to get a better understanding and get details to feedback about the research context. The contents of the interview include the situation of students' target language, learning experiences of Chinese initials, understanding of initials, students' difficulties and problems in learning Chinese initials, the reason for learning Chinese, the length of the study, the method of practicing initials after class, etc.

Thirdly, to compare the similarities and differences between Bangla and Chinese consonants system, the research also used the comparative analysis method. Therefore, it will help investigate the reason for the initials errors and predict the possible errors that Bangladeshi Chinese learners may have when learning Chinese initials.

\section{Results and Discussion}

\subsection{Data Presentation}

Table 1. Percentages and types of initials errors of Bangladeshi Chinese learners

\begin{tabular}{lllll}
\hline Consonants & Words & Form of errors & Error rate \\
\hline Labial & $\mathrm{b}[\mathrm{p}]$ & 帮 bāng, 表 biăo,病 bìng & {$[\mathrm{b}],[\mathrm{p}$ '] } & $\mathbf{3 0 \%}$ \\
\hline
\end{tabular}




\begin{tabular}{|c|c|c|c|c|}
\hline \multirow[t]{2}{*}{ consonants } & $\mathrm{p}\left[\mathrm{p}^{\mathrm{h}}\right]$ & 朋 péng,票 piào & {$[\mathrm{p}],[\mathrm{f}]$} & $40 \%$ \\
\hline & $f[f]$ & 放 fàng,父 fù & [p'] & $20 \%$ \\
\hline \multirow{2}{*}{$\begin{array}{l}\text { Alveolar } \\
\text { consonants }\end{array}$} & $\mathrm{d}[\mathrm{t}]$ & 带 dài,懂 dǒng & {$[\mathrm{d}],\left[\mathrm{t}^{\prime}\right]$} & $35 \%$ \\
\hline & $\mathrm{t}\left[\mathrm{t}^{\mathrm{h}}\right]$ & 同 tóng,头 tóu & {$[\mathrm{t}]$} & $20 \%$ \\
\hline \multirow{2}{*}{$\begin{array}{l}\text { Velar } \\
\text { consonants }\end{array}$} & $\mathrm{g}[\mathrm{k}]$ & 床高 gāo, 光 guāng & [g] & $45 \%$ \\
\hline & $\mathrm{k}\left[\mathrm{k}^{\mathrm{h}}\right]$ & 看 kàn,kăo 考 & {$[\mathrm{k}]$} & $25 \%$ \\
\hline \multirow{3}{*}{$\begin{array}{l}\text { Alveo-Palatal } \\
\text { consonants }\end{array}$} & $\mathrm{j}[\mathrm{t} 6]$ & 叫 Jiào,姐 jiě, 卷 juăn & {$[\mathrm{d} z],[\mathrm{ts}],[[\mathrm{tcc}]$} & $38 \%$ \\
\hline & $\mathrm{q}\left[\mathrm{t} 6^{\mathrm{h}}\right]$ & 钱 qián,穷 qióng & {$\left[\mathrm{d} 3^{\prime}\right],[\mathrm{t}$ ç],[ts'] } & $35 \%$ \\
\hline & $x[6]$ & 想 xiăng,笑 xiào,修 xiū & {$[\mathrm{t}$ ç],[ts'] } & $45 \%$ \\
\hline \multirow{4}{*}{$\begin{array}{l}\text { Retroflex } \\
\text { consonants }\end{array}$} & $\mathrm{zh}[\mathrm{ts}]$ & 中 zhōng,桌 zhuō & {$[\mathrm{t} f],[\mathrm{d} 3]$} & $90 \%$ \\
\hline & $\operatorname{ch}\left[\mathrm{ts}^{\mathrm{h}}\right]$ & 吃 chī, 床 chuáng & {$[\mathrm{ts}],[\mathrm{t} f]$} & $85 \%$ \\
\hline & $\operatorname{sh}[\mathrm{s}]$ & 生 shēng, 说 shuō, 谁 shéi & {$[\mathrm{s}],\left[\int\right],[\mathrm{tcc}]$} & $80 \%$ \\
\hline & r/d/ & 然 rán,热 rè & $/ \mathrm{r} /$ & $20 \%$ \\
\hline \multirow{3}{*}{$\begin{array}{l}\text { Dental } \\
\text { consonants }\end{array}$} & $\mathrm{z}[\mathrm{ts}]$ & 早 zăo, 走 zǒu & {$[\mathrm{d} z],[\mathrm{t}],\left[\mathrm{ts}^{\prime}\right]$} & $75 \%$ \\
\hline & $\mathrm{c}\left[\mathrm{ts}^{\mathrm{h}}\right]$ & 菜 cài, 层 céng,错 cuò & {$[\mathrm{s}],[\mathrm{c}],[\mathrm{ts}],[\mathrm{S}]$} & $60 \%$ \\
\hline & $\mathrm{s}[\mathrm{s}]$ & 伞 săn,送 sòng & {$[\mathrm{ts}],\left[\mathrm{ts}^{\prime}\right],\left[\int\right]$} & $55 \%$ \\
\hline
\end{tabular}

It shows that the error rate of the initial consonant of Bangladeshi students is more than $30 \%$ in 15 initials such as labial, velar, dental, palatal sound, etc. The researcher also found that more than $50 \%$ of error occurs in 5 initials while more than $80 \%$ in 3 initials.

Therefore, the error rate of Bangladeshi students in Chinese initials is high. The highest error rate occurs in the pronunciation of retroflex consonants. For example, zh has the highest error rate that is $90 \%$ while the second highest is ch as many as $85 \%$. However, retroflex consonant $\mathrm{sh}$ is $80 \%$. The lowest error rate occurs in the retroflex $\mathrm{r}$ consonant that is only $20 \%$.

Besides, the percentages of dental consonants such as z, c, s are $55 \%$ to $75 \%$. On the other hand, the percentages of errors in producing palatal sounds such as j, q, x are $35 \%$ to $45 \%$. Moreover, the error rate of aspirated sounds is generally higher than that of non-aspirated sounds. For example, for labial consonants $\mathrm{b}$ and $\mathrm{p}$, alveolar consonant $\mathrm{d}$ and $\mathrm{t}$, as well as the velar consonant $\mathrm{g}$ and $\mathrm{k}$, their percentages of errors are $30 \%, 40 \%, 35 \%, 20 \%, 45 \%$ and $25 \%$ etc.

Besides, data also shows that students did not make any mistakes in 6 consonants such as labial consonant $\mathrm{m}$, alveolar consonant $\mathrm{n}$, velar consonant $\mathrm{h}$ and $\mathrm{l}$, special consonants $\mathrm{w}$ and $\mathrm{y}$ and the error rate is zero.

However, the highest error occurs in retroflex, dental, and palatal consonants. Errors occur due to the absence of this phonetic feature in their mother language Bangla. Moreover, Bangladeshi students do not know the actual place of articulation of these consonants. As a result, they are often confused during the pronunciation of these consonants. On the other hand, an error occurs in the aspirated consonants due to the influence of English consonants 


\section{Macrothink}

International Journal of Linguistics

ISSN 1948-5425

2021, Vol. 13, No. 3

as learners pronounce Chinese initials b, $\mathrm{d}, \mathrm{g}$ as the same as Bangla consonants.

So it's proved again, the negative transfer of the mother tongue is indeed the main factor of pronunciation errors in the Chinese initials of Bangladeshi learners.

\subsection{Types of Initials Errors of Bangladeshi Learners}

From the data analysis, the common types of initial consonants errors of Bangladeshi students are voiceless-voiced, aspirated-unaspirated, dental, alveolar, and retroflex sounds, etc. There are 22 consonants in the Chinese language. Among these in 17 consonants, Bangladeshi students make an error during the speaking. For example,

(1) Voiceless consonants pronounced as voiced consonants

The most common error of initials made by Bangladeshi students is voiceless sound becomes voice sound. They produce voiceless consonants b, d, g as voiced consonants. For example,

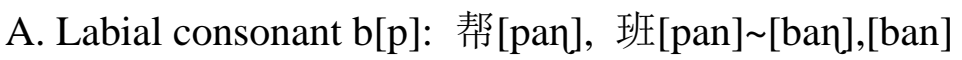

$$
/ \mathrm{p} / \sim / \mathrm{b} /
$$

B. Alveolar consonant d[t]: 带[tài]，懂[tǒng] [dai],[don]

$$
/ \mathrm{t} / \sim / \mathrm{d} /
$$

C. Velar consonant $\mathrm{g}[\mathrm{k}]$ : 高[kāo], 光[kuāng] [gao],[guan]

$$
/ \mathrm{k} / \sim / \mathrm{g} /
$$

Here, in the first example, (A) shows that voiceless bilabial $\mathrm{b} / \mathrm{p} / \mathrm{become}$ voiced $/ \mathrm{b} /$. The second example (B), shows that voiceless denti-alveolar $\mathrm{d} / \mathrm{t} /$ become voiced alveolar $/ \mathrm{d} /$. On the other hand, the third example (C) shows that voiceless velar $\mathrm{g} / \mathrm{k} /$ become voiced /g/.

This type of errors occurs because labial $\mathrm{b}[\mathrm{p}]$, denti-alveolar $\mathrm{d}[\mathrm{t}]$ and velar $\mathrm{g}[\mathrm{k}]$ referred as the Bangla consonants $/ \mathrm{b} /, / \mathrm{d} /$ and $/ \mathrm{k} /$. The influence of the mother tongue has become the main reason for initials errors in Bangla consonants.

(2) Aspirated pronounced as an un-aspirated sound

Another type of error made by Bangladeshi learners is the wrong pronunciation of the aspirated sound. Bangladeshi learners get confused during produced the aspirated sounds. For example, some common errors occur during the pronunciation of aspirated $\mathrm{p}, \mathrm{t}, \mathrm{k}$ sounds. For example,

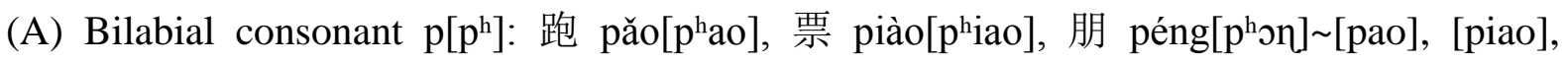
[fon]

$$
/ \mathrm{p}^{\mathrm{h} / \sim / \mathrm{p} /, / \mathrm{f} /}
$$

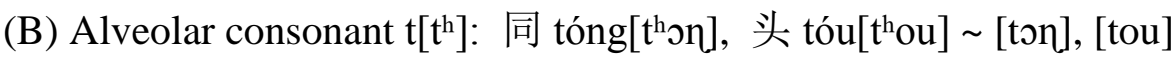

$$
/ \mathrm{t}^{\mathrm{h}} / \sim \mathrm{t} /
$$


(C) Velar consonant $\mathrm{k}\left[\mathrm{k}^{\mathrm{h}}\right]$ : 看 $\mathrm{kàn}\left[\mathrm{k}^{\mathrm{han}}\right]$ ，考 $\mathrm{kăo}\left[\mathrm{k}^{\mathrm{hao}}\right] \sim[\mathrm{kan}]$, [kao]

$$
/ \mathrm{k}^{\mathrm{h} / \sim \mathrm{k} /}
$$

Here, in the first example, (A) shows that Chinese initial aspirated bilabial consonant $\mathrm{p} / \mathrm{p}^{\mathrm{h}} /$ produced as un-aspirated /p/ or fricative /f/. In the second example, (B) shows that aspirated denti-alveolar $\mathrm{t} / \mathrm{t}^{\mathrm{h}} /$ pronounced as un-aspirated $/ \mathrm{t} /$. In the last example, (C) aspirated velar $\mathrm{k} / \mathrm{k}^{\mathrm{h}} /$ produced an unaspirated $/ \mathrm{k} /$ sound. However, Chinese aspirated consonants $\mathrm{p}\left[\mathrm{p}^{\mathrm{h}}\right], \mathrm{t}\left[\mathrm{t}^{\mathrm{h}}\right]$, and $\mathrm{k}\left[\mathrm{k}^{\mathrm{h}}\right]$ are also referred to as unaspirated consonants in Bangla. As a result, Bangladeshi learners of Chinese easily make mistakes in producing these aspirated consonants. This error is also the result of the negative transfer of the first language.

(3) Problem with retroflex, alveo-palatal, and Dental sounds

Initials error also occurs in dental, alveolar, and retroflex sounds in the pronunciation of Bangladeshi learners.

A. In initial consonants, retroflex consonants $\mathrm{zh}, \mathrm{ch}$, sh have the highest error rate, reaching more than $90 \%$, and there are many forms of errors (Li, 2016). For example.

\begin{tabular}{|c|c|c|c|}
\hline Initial consonant & words & Pronounced as & Types of error \\
\hline $\operatorname{ch}\left[\mathrm{ts}^{\mathrm{h}}\right]$ & 吃 chī, 茶 chá, 车 chē & {$[\mathrm{t} f \mathrm{i}],[\mathrm{tsa}],\left[\mathrm{t} \int \mathrm{D}\right]$} & {$[\mathrm{ts}],\left[\mathrm{t} \int\right]$} \\
\hline $\operatorname{sh}[\mathrm{s}]$ & 手 shǒu, 谁 shéi, 山 shān & 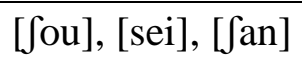 & {$[\mathrm{s}],[\mathrm{S}],[\mathrm{tç}]$} \\
\hline $\mathrm{zh}[\mathrm{ts}]$ & 张 zhāng, 中 zhōng, 桌 zhuō & [dzan], [tfuo] & {$\left[\mathrm{t} \int\right],[\mathrm{d} 3]$} \\
\hline
\end{tabular}

Here, Bangladeshi have difficulties in Chinese retroflex sounds because, in Bangla, there are no sounds like $\mathrm{zh}, \mathrm{ch}$, sh. To pronounce the retroflex consonants, the position of the tongue needs to go back. Most Bangladeshi students fail to do it correctly. As a result, the pronunciation of $\mathrm{zh}$ pronounces as $\left[\mathrm{t} \int\right],\left[\mathrm{d}_{3}\right]$ and ch pronounce as [ts], [t $\left.\mathrm{t}\right]$. Among these three fricatives, sh consonant presents in both Chinese and Bangla, but the place of articulation is different. As an influence of the mother tongue, Bangladeshi students pronounce Chinese sh[s] as [s] or [S] that exist in Bangla.

There is another initial $\mathrm{r} / \mathrm{d} /$ in Chinese is a retroflex fricative sound, which is different from trill consonant $\pi / \mathrm{r} /$ and flap consonants $ড ়, \underline{T} / \mathrm{r} /$ in the Bangla consonants. As a result, Bangladeshi learners of Chinese make errors in pronouncing these initials.

B. Bangladeshi students also encounter difficulties with the accurate pronunciation of alveo-palatal sounds such as j, q, x. This type of error is also known as an aspirated and un-aspirated sound problem. However, alveo-palatal consonants $\mathrm{j}$, q, and x pronounce with the tip of the tongue. During producing these initials, learners need to add a [i] vowel such as Ji, qi, xi. Moreover, Bangladeshi learners' errors in producing these sounds are similar in the pronunciation of the English alphabet j, q, and x. For example, jiě [tcie,] [tsie], qián[t.6 hien] [[tçien], xiào[ciao] [tçiao] etc.

C. Another difficulty of Bangladeshi students encounter when they try to pronounce the dental sounds. For Bangladeshi learners' of Chinese, the second-highest error rate occurs in the pronunciation of dental sounds $\mathrm{z}, \mathrm{c}$, and s. This type of error is also related to 
aspirated and un-aspirated sound problems. For example:the pronunciation of c becomes [s], [c], [ts], s becomes [ts], [J], z becomes [dz]. For example:

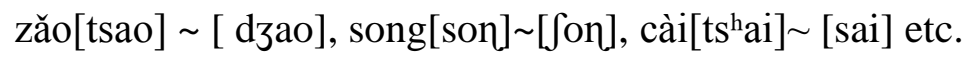

Among three dental consonants, only s consonant presents in the Bangla consonants. The pronunciation of Bangla consonant $s$ is different from Chinese, the place of articulation and pronunciation method is also different.

D. Chinese consonant labio-dental $\mathrm{f}$ also not present in Bangla. It exists in the English alphabet. As English is the second language of Bangladesh, it is not hard to pronounce for Bangladeshi learners. The error rate is also low in this initial.

\subsection{Comparison Between Bangla and Chinese Consonant Systems}

Though both Bangla and Chinese have consonants, the consonants of these languages are not the same. They have different pronunciations with the places and the manner of articulation. As already mentioned above that, these two languages originated from different language families. Based on the place and manner of articulation, they have some similarities and differences. To know the similarities and differences between Bangla and Chinese initials, the researcher needs to go through the comparison of pronunciation methods and articulation. Here, the researcher will present the consonants system of Chinese and Bangla according to their linguistic features.

\subsubsection{Standard Chinese Consonant}

There is some disagreement about the number of Chinese initials among linguists and scholars. According to Huang \& Liao (2017), Wang and Lin (2007) stated Chinese has 22 consonants with one-syllable coda -ng. "The consonants of Chinese comprise six plosives, two nasals, five fricatives, six affricates, one lateral approximant and these sum up to twenty-one consonants" (Eme \& Odinye, 2008:30).

According to the Beijing standard, there are 21 consonants in Chinese and one one-syllable coda - ng. The consonants of Chinese locate at the beginning of Chinese Pinyin. The pronunciation of consonants analyzes according to place and manner of articulation. Based on the place of articulation, Chinese initials are seven types. These are: bilabial, labiodental, dental, alveolar, retroflex, alveolo-palatal, and velar. In terms of the manner of articulation, Chinese standard initials are five types. These are stop, affricate, and fricative, nasal and lateral. The linguistics features of Chinese consonants are given below:

Table 2. Standard Chinese consonant chart

\begin{tabular}{|c|c|c|c|c|c|c|c|c|c|c|c|}
\hline \multirow{2}{*}{\multicolumn{2}{|c|}{$\begin{array}{l}\text { Manner of articulation } \\
\text { Place of articulation }\end{array}$}} & \multicolumn{2}{|l|}{ Bilabial } & \multirow{2}{*}{$\begin{array}{l}\text { Labiodental } \\
\text { Voiceless } \\
\end{array}$} & \multirow{2}{*}{$\begin{array}{l}\text { Dental } \\
\text { Voiceless }\end{array}$} & \multirow{2}{*}{$\begin{array}{l}\text { Alveolar } \\
\text { Voiceless }\end{array}$} & \multirow{3}{*}{ Voiced } & \multicolumn{2}{|l|}{ Retroflex } & \multirow{3}{*}{$\begin{array}{l}\text { Alveo-palatal } \\
\text { Voiceless } \\
\end{array}$} & \multirow{3}{*}{$\begin{array}{l}\text { velar } \\
\text { Voiceless } \\
\mathrm{g}[\mathrm{k}]\end{array}$} \\
\hline & & Voiceless & voiced & & & & & Voiceless & Voiced & & \\
\hline Stop & Unaspirated & $\mathbf{b}[\mathrm{p}]$ & & & & $d[t]$ & & & & & \\
\hline & Aspirated & $\mathrm{p}\left[\mathrm{p}^{\mathrm{h}}\right]$ & & & & $\mathrm{t}\left[\mathrm{t}^{\mathrm{b}}\right]$ & & & & & $\mathrm{k}\left[\mathrm{k}^{\mathrm{h}}\right]$ \\
\hline \multirow[t]{2}{*}{ Affricate } & Unaspirated & & & & $\mathrm{z}[\mathrm{ts}]$ & & & $\mathrm{zh}[\mathrm{ts}]$ & & $\mathrm{j}\left[\mathrm{t}_{6}\right]$ & \\
\hline & Aspirated & & & & $c\left[\mathrm{ts}^{\mathrm{b}}\right]$ & & & $\operatorname{ch}\left[\mathrm{ts}^{\mathrm{b}}\right]$ & & $\mathrm{q}\left[\mathrm{t}_{6^{\mathrm{h}}}\right]$ & \\
\hline Fricative & & & & $\mathrm{f}[\mathrm{f}]$ & $s[s]$ & & & $\operatorname{sh}[s]$ & $r / t /$ & $x[6]$ & $\mathrm{h}[\mathrm{x}]$ \\
\hline Nasal & & & $\mathrm{m}[\mathrm{m}]$ & & & & $\mathrm{n}[\mathrm{n}]$ & & & & \\
\hline Lateral & & & & & & & $1[1]$ & & & & \\
\hline
\end{tabular}




\section{Al Macrothink}

International Journal of Linguistics

ISSN 1948-5425

2021, Vol. 13, No. 3

\subsubsection{Bangla Consonant Chart}

Compared to Chinese initials, the initials of the Bangla language is more complicated.In Bangla language, there are 39 consonants, namely

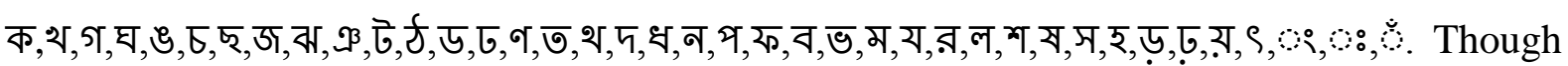
the number of the consonant in Bangla is 39, the actual pronunciation of the Bangla consonant is only 30 .

There is a dispute between linguists and researchers about the number of Bangla consonants. According to Hai (2007), Bangla has 36 consonants such as 20 stops, 7 fricatives, 4 nasals, 1 lateral, 1 trill, 2 flaps, 1 glide wheres Haque (2002) mentioned that there are 35 consonants exist in Bangla. These are 21 stops, 5 fricatives, 3 nasals, 1 lateral, 1 trill, 2 flaps, 2 glides. On the Other hand, Morshed (2001) claimed that the number of Bangla consonants is 31 that are 20 stops, 4 nasals, 4 fricatives, 1 lateral, 2 flaps. However, Ali(2001) showed that Bangla has 32 consonants such as 20 stops, 3 nasals, 3 fricatives, 1 lateral, 2 flaps, 1 trill, 2 glides.

According to the place of articulation, Bangla consonants are seven main types. These are bilabial, dental, alveolar, post-alveolar, palatal, velar, and glottal sounds. In terms of the manner of articulation, Bangla consonants are seven types. These are Stop, fricative, nasal, lateral, trill, flap, and approximant sounds. Here, the researcher will present the Bangla consonants based on the standard consonant phonemes.

Table 3. Bangla Standard consonant chart

\begin{tabular}{|c|c|c|c|c|c|c|c|c|}
\hline \multicolumn{2}{|c|}{$\begin{array}{l}\text { Manner } \\
\text { articulation } \\
\text { Place } \\
\text { articulation } \\
\end{array}$} & Bilabial & dental & Alveolar & Post-alveolar & Palatal & Velar & Glottal \\
\hline \multirow[t]{4}{*}{ Stop } & Voiceless & भ/p/ & $\overline{ত /[t] ~}]$ & ট/t/ ঠ/th/ & চ/c/ চ্ছ/ch/ & & ক/k/ & \\
\hline & & र/ph/ & V/th/ & & & & 2/kh/ & \\
\hline & Voiced & ব/b/ & দ/d/, & ড/d/ & য,জ/J/ ঝ/গh/ & & গ/g/ & \\
\hline & & ভ/bh/ & $\left.\varepsilon / \mathrm{d}^{\mathrm{h}}\right]$ & ঢ/dh/ & & & घ/gh/ & \\
\hline \multicolumn{2}{|c|}{ Fricative } & & & শ,স/s/ & & শ, স,স/ু/ & & ₹/h/ \\
\hline \multicolumn{2}{|c|}{ Nasal } & ম/m/ & & ন,ণ/n/ & & & ঙ/y/ & \\
\hline \multicolumn{3}{|c|}{ Lateral } & & ল/l/ & & & & \\
\hline \multicolumn{3}{|l|}{ Trill } & & র/r/ & & & & \\
\hline
\end{tabular}


Flap

$ড, \bar{\zeta} / \mathrm{/} /$

Approximant

য়/j/

However, in terms of the vibration of the vocal cord, Bangla consonants are classified into 2 types: voiced and voiceless consonant. For example:

Voiced: [b], [bh], [d], [d్ $\left.{ }^{\mathrm{h}}\right],[\mathrm{d}],[\mathrm{dh}],[\mathrm{f}],[\mathrm{\jmath h}],[\mathrm{g}],[\mathrm{gh}],[\mathrm{m}],[\mathrm{n}],[\mathrm{y}],[1],[\mathrm{r}],[\mathrm{r}],[\mathrm{j}]-17$

Voiceless: [p], [ph], [t] $\left.{ }_{\text {. }} \mathrm{th}_{n}^{\mathrm{h}}\right],[\mathrm{t}],[\mathrm{th}],[\mathrm{c}],[\mathrm{ch}],[\mathrm{k}],[\mathrm{kh}],[\mathrm{s}],[\mathrm{J}],[\mathrm{h}]-13$

Besides, there are also two types of consonants naming aspirated and un-aspirated consonants. Based on the strength of airflow. These are:

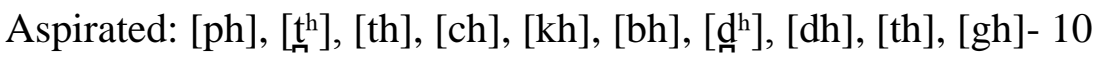

Unaspirated: [p], [t] $,[\mathrm{t}],[\mathrm{k}],[\mathrm{b}],[\mathrm{d}],[\mathrm{d}],[\mathrm{g}],[\mathrm{c}],[\mathrm{f}]-10$

\subsubsection{Comparison of Chinese and Bangla Consonants}

Though the Chinese and Bangla language are originated from different language families, still they have some similarities and differences. In this research, by using comparative analysis, the researcher tried to represent the similarities and dissimilarities between these two languages. Therefore, the unique features of Chinese consonants can be regarded as the difficulties of Bangladeshi students in acquiring Chinese consonants. Comparing Chinese and Bangla consonants system, the following conclusion can be drawn:

(1) The number of consonants in Bangla and Chinese are different. In Bangla, there are 39 consonants where the actual pronunciation of consonants is 30. In contrast, Chinese has 22 consonants including -ng (syllable coda).

(2) The number of Voiced sounds in Bangla is more than in Chinese. There are only 4 voiced sounds such as $\mathrm{m}, \mathrm{n}, 1, \mathrm{r}$, in Chinese whereas among the 30 consonants in Bangla, there are 17 voiced consonants. On the other hand, there are 6 plosives, 6 affricates, and 6 fricatives in the language that are equally distributed, and they are all voiceless without $r / £ /$. In Bangla, there are 20 plosives and they have both voiced and voiceless consonants. Moreover, there are 6 pairs of aspirated and non-aspirated consonants n Chinese while Bangla has 10 pairs.

(3) From the perspective of the place of articulation, There are some consonants present in Chinese initials, but not present in Bangla consonants. For example: retroflex consonants $\mathrm{zh}[\mathrm{ts}], \operatorname{ch}\left[\mathrm{ts}^{\mathrm{h}}\right], \mathrm{sh}[\mathrm{s}], \mathrm{r} / \mathrm{d} /$ dental consonants $\mathrm{z}[\mathrm{ts}], \mathrm{c}\left[\mathrm{ts}^{\mathrm{h}}\right], \mathrm{s}[\mathrm{s}]$, alveo-palatal j[t6], $\mathrm{q}\left[\mathrm{t}_{6^{\mathrm{h}}}\right], \mathrm{x}[\mathrm{6}]$, labiodental $\mathrm{f}[\mathrm{f}]$, velar $\mathrm{h}[\mathrm{x}]$ etc.

(4) All the consonants in Bangla are pronounced with a vowel sound [0] wheres initials are followed by different sounds such as [o], [i], [2], and [1] sounds in Chinese.

(5) Consonant $\mathrm{r}[\mathrm{z}]$ in Chinese is a retroflex fricative sound, which is different from trill

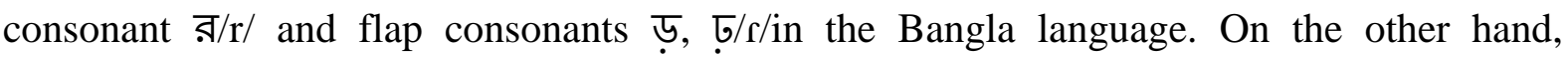


consonants $\mathrm{s}[\mathrm{s}]$ in Chinese is a dental fricative which is also different from Bangla শ,স[s] and শ,স,ষ[ভ]. Their place and manner of articulation is also different from Chinese.

(6) Bangla and Chinese have some similar consonants but different pronunciation such as:

Chinese consonants Bangla consonants

$\mathrm{b}[\mathrm{p}] \mathrm{b}$ in Bangla pronounced as voiced $[\mathrm{b}]$

$\mathrm{d}[\mathrm{t}] \mathrm{d}$ in Bangla pronounced as voiced $[\mathrm{d}]$

$\mathrm{g}[\mathrm{k}] \mathrm{g}$ in Bangla pronounced as voiced $[\mathrm{g}]$

\section{Reasons for Committing Errors in Chinese Initials}

Through the analysis of Chinese initials errors, the researcher summarized that the errors are mainly due to the following reasons:

\subsection{Negative Transfer of Mother Language and English}

The most important reason for the initial errors of Bangladeshi learners is the influence of their first language. Second language learners are most affected by the transfer of their mother tongue in the early learning stage. The influences of the transfer of the mother tongue will be weakened by the course of time and the eagerness of learning. At the beginning of learning Chinese, learners usually acquire Chinese pronunciation first.

Some similarities present between the consonant systems of Chinese and Bangla. Therefore, the similarities cause the negative transfer of the mother tongue in the course of the study. For example Bangla and Chinese both have some similar phonetic symbols like b, p, t, d, k, g with a different pronunciation. As a result, initials errors such as voiceless becomes voiced, aspirated becomes un-aspirated occur in the pronunciation of Bangladeshi Chinese learners. So the influence of the mother tongue has become the main reason for initials errors in Bangla consonants.

Another reason for the initial errors of Bangladeshi students is most of the Bangladeshi students' do not realize the difference between the pronunciation of Chinese Pinyin and English. As English is the second most prior language in Bangladesh, all the learners are familiar with the consonants of English. As a result, during producing Chinese initials, they follow the pronunciation of English consonants. The reason behind this problem is the negative transfer of the English language. Students confuse the Chinese pinyin and English consonants and read the Chinese pinyin directly according to the pronunciation of the English letters, such as [baba] and [dai] instead of [papa] and [tai].

\subsection{Errors Caused by Similar Phonetic Symbols}

As already mentioned above that, Chinese and Bangla consonants systems have some similarities and differences. So the similar features of the target language are easy to acquire for learners. However, sometimes these similarities also responsible for making mistakes. For 
example, some similar phoneme symbols present in both languages, but they have different pronunciations. These are:

$\mathrm{b}[\mathrm{p}]: \mathrm{b}$ in Bangla pronounced as voiced $[\mathrm{b}]$

$\mathrm{d}[\mathrm{t}]$ : $\mathrm{d}$ in Bangla pronounced as voiced $[\mathrm{d}]$

$\mathrm{g}[\mathrm{k}]: \mathrm{g}$ in Bangla pronounced as voiced $[\mathrm{g}]$

$\mathrm{p}[\mathrm{ph}]: \mathrm{p}$ in Bangla pronounced as un-aspirated voiceless [p]

$\mathrm{t}[\mathrm{th}]: \mathrm{t}$ in Bangla pronounced as un-aspirated voiceless $[\mathrm{t}]$

$\mathrm{k}[\mathrm{kh}]: \mathrm{k}$ in Bangla pronounced as un-aspirated voiceless [k]

Although these Chinese initials present in the Bangla language, students are easily disturbed by recorded phonetic symbols. For example, Chinese bǐ [pi] pronounced as [bi], dànshì [tan $\left.\int i\right]$ pronounced as [dan $\sqrt{1}]$. So, phonetic symbols are responsible for the mispronunciation of these initials.

\subsection{Differences Between Chinese and Bengali Consonants}

Bangla and Chinese have different consonant systems, and the number of consonants is also different. Few pairs of Chinese initials not present in Bangla consonants. For example: retroflex consonants zh, sh, ch, palato-alveolar consonants $\mathrm{j}, \mathrm{q}, \mathrm{x}$, dental consonant $\mathrm{z}, \mathrm{c}, \mathrm{s}$ etc. The error rate of Bangladeshi learners is high in these three pairs of initials. According to Lado (1957), in second language acquisition, those features that have similarities to the mother tongue are easy to learn, and differences with the mother tongue are difficult to learn. As a result, students often encounter difficulties pronouncing these initials accurately.

\subsection{Errors Caused by Pronunciation Habits and Methods}

Another main reason for Chinese initials error is the different pronunciation habits and methods. All the consonants in Bangla pronounce with a vowel [॰]. To make it easier to pronounce, different initials in Chinese use different vowels. For example:

$\mathrm{b}, \mathrm{p}, \mathrm{m}, \mathrm{f}$ is followed by [o] such as bo, po, mo.

$\mathrm{d}, \mathrm{t}, \mathrm{n}, \mathrm{l}, \mathrm{g}, \mathrm{k}, \mathrm{h}$ followed by [e] such as de, te, ge.

$\mathrm{j}, \mathrm{q}, \mathrm{x}$ followed by [i] such as ji, qi, xi.

zh, ch, sh, r followed with -i[น] as zhi, chi, shi.

z, c, s followed with a -i[?] such as zi, ci, si.

Moreover, there are some methods to produce Chinese initials accurately. Bangladeshi learners don't understand or follow the correct pronunciation methods. To pronounce Chinese initials correctly, learners need to know the pronunciation methods. For example:

Retroflex sounds zh, ch, sh: produce with the tip of the tongue and curled farther back. 
Palato-alveolar sounds $\mathrm{j}, \mathrm{q}, \mathrm{x}$ : produce with the tip of the tongue and tongue touches the lower front teeth.

Retroflex $r$ sound: pronounced with the tip of the tongue curled farther back and lips unrounded.

Dental sounds z, c, s: produce with the tip of the tongue and tongue touches the upper front teeth. These are the most difficult initials sounds in Chinese initials. The learners of second language encounter difficulties acquiring the correct pronunciation methods.

\subsection{Problem With Aspirated- Unaspirated Sounds}

In the pronunciation of Chinese initials of Bangladeshi learners, among the error types of initials, the most common error occurs in three aspirated sounds such as $\mathrm{p}, \mathrm{t}$, and $\mathrm{k}$ become aspirated sounds such as $\mathrm{p}[\mathrm{b}], \mathrm{t}[\mathrm{d}], \mathrm{g}[\mathrm{k}]$. Aspirated non-aspirated errors occur because students do not understand the distinguishing characteristics of aspirated and non-aspirated Chinese pinyin. As a result, an error occurs in the pronunciation of Chinese initials. Moreover, the difficulty of the pronunciation of dental sounds $\mathrm{z}, \mathrm{c}, \mathrm{s}$, and alveo- palatal j, q, x sounds are also classified as aspirated -unaspirated sound problems.

\subsection{Differences in Learning Motivation and Learning Strategy}

Everyone has different purposes and motivations in learning Chinese. The learning motivation and learning strategies of Bangladeshi students influence their Chinese pronunciation. If the learning strategy is different, the learning effect may be different. In Bangladesh, some students learn Chinese for getting a good job in the future while some students learn Chinese for getting a scholarship in China. Most of the students learn Chinese only for communication. They don't give importance to the standard pronunciation of Chinese phonetics. If they can communicate in Chinese with others, they are satisfied with their proficiency level. As a result, errors of initials consonants occur in the pronunciation of Bangladeshi learners.

\section{Possible Teaching Strategies of Chinese Initials for Bangladeshi Learners}

Through data analysis, the researcher found that Bangladeshi students face difficulties in producing Chinese initials such as retroflex, dental, and palato -alveolar sounds. Learners' error includes in the aspirated-unaspirated, voiced-unvoiced and the methods of pronunciations, etc. To help Bangladeshi Chinese learners acquiring initials, the following teaching suggestions may be useful for learners.

1) Voiced-unvoiced sounds problem

In the process of Chinese phonetic teaching, at first, teachers should explain the different pronunciations of Chinese and Bangla consonants phonemes. The teacher should explain the importance of the actual position of the tongue. Students should understand the difference between voiced-unvoiced sounds, and pronunciation methods. Besides, teachers may give priority to correct student's errors when they produce incorrectly. To reduce learner's 
voiced-unvoiced errors, teachers may use modern technology like Pratt speech software. It could be a useful tool for learners to correct their initials errors.

2) Aspirated- unaspirated sounds problem

To avoid the error of aspirated and unaspirated sounds, teachers need to explain the difference between aspirated and un-aspirated sounds and the difference in pronunciation methods. For that, teachers may follow the blowing paper method. To follow this method, fold a thin piece of paper in half and place it in front of lips, ask students to pronounce aspirated and un-aspirated sounds. For example, teachers can ask students to pronounce words that contain consonants $\mathrm{b}$ and $\mathrm{p}, \mathrm{d}$ and $\mathrm{t}, \mathrm{g}$ and $\mathrm{k}$, zh, and ch consonants such as bàn, pán, diàn, tián, guān, kōng, jiǔ, qiū, zhōng, chūn, etc. This method is more visual to observe the vibration of the paper. It will help learners to practice and to understand the difference between the aspirated and un-aspirated sounds.

\section{3) Dental, retroflex and alveo-palatal sounds Problem}

Bangladeshi learners face difficulties in producing retroflex, dental, and alveo-palatal sounds. Moreover, the highest error rate is also found in these consonants pairs. To reduce the error rate of these consonants, teachers need to use effective visual methods.

At first, the teacher may demonstrate the different positions of the tongue while pronouncing these consonants. The teacher also explains that the position of the tongue is different for these three types of consonants. For example, when pronouncing palato-alveolar $\mathrm{j}, \mathrm{q}, \mathrm{x}$ consonants, teachers should emphasize the position of the tip of the tongue. On the other hand, retroflex consonants $\mathrm{zh}, \mathrm{ch}$, sh, are produced with the tip of the tongue and curled farther back. Furthermore, dental consonants z, c, s are produced with the tip of the tongue and tongue touches the upper front teeth. In Bangla consonants, there are no sounds like zh, ch, sh, z, c, s. So, it is difficult for Bangladeshi students to learn these consonants. To simulate the position of the tongue, the teacher can also use hand movements like the movement of the tongue can be shown by two hands, which will be more helpful for learners to understand. Besides, teachers may also visually show students the shape of the tongue, and palate during pronunciation. This method will be helpful for Bangladeshi learners to master these consonants.

To pronounce these consonants, learners must make sure that the place of articulation needs to be appropriate. Finally, students need to do the drill as much as possible.

\section{Conclusion}

In this current research, initials errors of Bangladeshi Chinese learners have been discussed. Simultaneously, based on the data analysis, types of initials errors and the reason behind these errors were also analyzed. Finally, the researcher proposed some effective teaching strategies to improve the pronunciation of initials errors of Bangladeshi learners. During the presentation of data, it has seen that the error rate in the Chinese initials of Bangladeshi learners is comparatively high. Bangladeshi learners encounter difficulties in the pronunciation of retroflex, dental, and palato-alveolar consonants. However, the highest rate of error occurs in the retroflex consonants. Bangladeshi learners have problems in the retroflex consonants because these sounds do not exist in the consonants of Bangla. However, 
the second-highest rate of error occurs in the dental consonants. Besides, the third-highest rate of error occurs in the pronunciation of palato-alveolar consonants. Their errors include voiceless becomes voiced, aspirated becomes unaspirated, and the pronunciation methods and way.

By data analysis, the researcher has found the reason behind these errors the negative transfer of mother tongue and English language, similar phonetic symbols, the difference between Chinese and Bangla consonants, lack of motivation and strategy etc.

Some limitations are also pointed out in this research. The number of participants is small. So the sample size has limitations to analysis the data. On the other hand, the researcher is also a non-native speaker of Chinese. From that point of view, there are also limitations of the actual pronunciation of Chinese initials. Despite all of the limitations, this research will help Bangladeshi Chinese learners to improve their initials learning. It will also support people who want to research this research area.

\section{References}

Ali. J. I. (2001). Introduction to phonetics. Mowla Brothers: Dhaka.

Candra, H., \& Sukma, Y. G. (2020). Chinese initial teaching scheme designed for Indonesian Beginners. RETORIKA: Journal Ilmu Bahasa, 6(1), 7-17. https://doi.org/10.22225/jr.6.1.1421.7-17

Corder, S. P. (1967). The significance of learners' errors. IRAL: International Review of Applied Linguistics in Language Teaching, 5(4), 161-170. https://doi.org/10.1515/irl.1967.5.1-4,161

Corder, S. P. (1974). Error analysis. London: Longman.

Duanmu, S. (2007). The phonology of standard Chinese (2nd ed.). New York: Oxford University Press.

Ellis, R. (1997). Review of Second language acquisition. USA: Oxford University Press.

Eme, C. A., \& Odinye, I. S. (2008). 'Phonology of standard Chinese and Igbo: Implications for Igbo students learning Chinese', in NKOA (Nkuzi Omumu Asusu). Awka: Amaka Dreams Ltd.

Hai, A. (1967). Phonology and Bangla Phonetics (10th ed.). Dhaka: Mullick Brothers.

Haque, D. M. (2002). Speaking of Linguistics. Dhaka: Mowla Brothers.

Hendrickson, J. M. (1987). Error correction in foreign language teaching: Recent theory, research and practice. In M. H. Long, \& J. C. Richards (Eds.), Methodology in TESOL: A book of reading (p. 357). Boston: Heinle \& Heinle.

Huang, B. R., \& Liao, X. D. (2017). Modern Chinese. Beijing: Higher Education Press.

James, C. (1998). Errors in language learning and use: Exploring error analysis. UK: Addison Wesley Longman.

Khorl, G. S., Mah, B. Y., \& Chow, V. F. T. (2017). Pronunciation errors in Mandarin among the engineering undergraduates: An analytical analysis. International Academic Research Journal of Social Science, 3(1), 71-76. 


\section{Macrothink}

International Journal of Linguistics

ISSN 1948-5425

2021, Vol. 13, No. 3

Lado, R. (1957). Linguistics across culture. Annrbor: University of Michigan Press.

Li, S. (2016). An investigation and analysis of Chinese initial consonants errors by Bangladeshi students. Kunming: Yunnan University.

Li, L. X. (2013). An analysis of the difficulties in the teaching of Chinese phonetics in Bangladesh. Kunming: Yunnan University.

Morshed, A. K. M. (2001). Adhunik bhasha tatto (8th ed.). Dhaka: Mowla Brothers.

Qin, B. (2014). Investigation and analysis of Chinese phonetics of Bangladesh BIT sixth grade students. Kunming: Yunnan University.

Ranjan, R. (2010). Chinese language acquisition in India: Error analysis and possible solutions. Department of Asian Languages: Hyderabad. Retrieved from https://www.efluniversity.ac.in/Journals-Asian\%20languages/2.\%20Article\%20CHINESE\%2 ORakesh.pdf

Sukarto, A. R. W., Renata, E., \& Moira, S. (2019). Contrastive analysis between Chinese and Indonesian phonology and implementation on conversation class. International Journal of Culture and Art Studies, 3(1), 1-14. https://doi.org/10.32734/ijcas.v3i1.1390

Wang, X., \& Chen, J. (2020). The acquisition of Mandarin consonants by English learners: The relationship between perception and production. Languages, 5(2), 20. https://doi.org/10.3390/languages5020020

Wang, X., \& Chen, J. (2019). English speakers' perception of Mandarin consonants: The effect of phonetic distances and L2 experience. In S. Calhoun, P. Escudero, M. Tabain, \& P. Warren (Eds.), Proceedings of the 19th International Congress of Phonetic Sciences, Melbourne, Australia 2019 (pp. 250-254). Canberra: Australasian Speech Science and Technology Association Inc.

Wang, L., \& Lin, T. (2007). Yuyun jiaocheng. Beijing: Beijing Daxue Chu Banshe.

Wang, J., Chen, Y. J., \& Hu, Y. T. (2019). Phonetic errors and teaching strategies in foreign students' Chinese learning. Contemporary Tourism.

$\mathrm{Xu}, \mathrm{Y}$. (2013). Phonetic error analysis and teaching counter measures of Indian junior high school and Chinese learners. Shandong Normal University.

Yang, C., \& Yu, A. C. L. (2019). The acquisition of Mandarin affricates by American L2 learners. Taiwan Journal of Linguistics, 17(2), 91-122. https://doi.org/10.6519/TJL.201907_17(2).0004

\section{Copyrights}

Copyright for this article is retained by the author(s), with first publication rights granted to the journal.

This is an open-access article distributed under the terms and conditions of the Creative Commons Attribution license (http://creativecommons.org/licenses/by/4.0/) 